\title{
Articles
}

\section{Revealing the cost of Type II diabetes in Europe}

\author{
B. Jönsson* \\ Centre for Health Economics, Stockholm School of Economics, Stockholm, Sweden
}

\begin{abstract}
Aims/hypothesis. 'The Cost of Diabetes in Europe Type II study' is the first coordinated attempt to measure total healthcare costs of Type II (non-insulindependent) diabetes mellitus in Europe. The study evaluated more than 7000 patients with Type II diabetes in eight countries - Belgium, France, Germany, Italy, the Netherlands, Spain, Sweden and the United Kingdom.

Methods. A bottom-up, prevalence-based design was used, which optimised the collection of data at the national level while maintaining maximum international comparability. Effort was made to ensure consistency in terms of data specification, data collection tools and methods, sampling design, and the analysis and reporting of results. Results are reported for individual countries and in aggregate for the total study population.

Results. The total direct medical costs of Type II diabetes in the eight European countries was estimated at EUR 29 billion a year (1999 values). The estimated
\end{abstract}

average yearly cost per patient was EUR 2834 a year. Of these costs, hospitalisations accounted for the greatest proportion (55\%, range 30-65\%) totalling EUR 15.9 billion for the eight countries. During the 6-month evaluation period, $13 \%$ of the Type II diabetic patients were hospitalised, with an average of 23 days in hospital projected annually. In contrast, drug costs for managing Type II diabetes were relatively low, with antidiabetic drugs and insulin accounting for only $7 \%$ of the total healthcare costs for Type II diabetes.

Conclusion/interpretation. Type II diabetes mellitus is a common disease and the prevalence is expected to increase considerably in the future, especially in developing countries. Current comprehensive economic data on the costs of diabetes are required for policy decisions to optimise resource allocation and to evaluate different approaches for disease management. [Diabetologia (2002) 45:S5-S12]

Keywords Type II diabetes, pharmacoeconomics, Europe.
Published online: 24 May 2002

(C) Springer-Verlag 2002

*B. Jönsson wrote on behalf of the CODE-2 Advisory Board

Corresponding author: Dr. B. Jönsson, Stockholm School of Economics, Box 6501, 11383 Stockholm, Sweden, E-mail: Bengt.Jonsson@hhs.se

Abbreviations: CODE-2, Cost of diabetes in Europe - Type II; DRG, diagnosis-related group; GP, general practitioner; HRQoL, health-related quality of life; ICD, international classification of diseases; ICU, intensive care unit; OECD, organization for economic co-operation and development.
Diabetes mellitus is a common disease and its prevalence is expected to increase in the future, especially in developing countries [1, 2]. As recently as 1995, an estimated 135 million people worldwide were affected by diabetes and by the year 2025 , this figure is projected to increase to approximately 300 million [3]. The majority of these diabetic patients (over 90\%) suffer from Type II (non-insulin-dependent) diabetes mellitus, which is by nature, a progressive disorder with a slow and insidious onset. As a consequence, the condition is frequently under reported [4] and, of the estimated 15.6 million adult diabetic patients in the United States, an estimated 5.4 million cases remain undiagnosed [5]. 
The control of Type II diabetes represents a considerable therapeutic challenge. The results of recent landmark studies, such as the United Kingdom Prospective Diabetes Study (UKPDS) [6] have shown that the relationship between glycaemic control and chronic complications is more complex than previously assumed. Long-term glycaemic control with currently available therapies remains an elusive target due to the progressive nature of the condition. Moreover, glycaemic control as evidenced by the reduction of $\mathrm{HbA}_{1 \mathrm{c}}$ with existing agents was found to have a weak and non-significant effect on the incidence of cardiovascular complications, although a correlation with the reduction of microvascular complications was noted. Consequently, one of the important messages to emerge from the study was that the management of Type II diabetes must be aimed at the comorbidities associated with the condition. Control of factors beyond the management of glycaemia (e.g. hypertension, hyperlipidaemia, insulin resistance, obesity) is vital in reducing the macrovascular complications.

Over the last 30 years, medical expenditure has increased throughout the world at a considerably faster rate than other sectors of the economy [7, 8]. It is estimated that the care of people with diabetes mellitus accounts for 4 to $5 \%$ of the total health budget of the United Kingdom. [9] A recent study by the American Diabetes Association showed that in 1997, diabetes accounted for $\$ 44.1$ billion in direct healthcare expenditures, $\$ 37.1$ billion in lost productivity due to disability and $\$ 17.0$ billion from lost productivity due to premature mortality [10]. Of the diabetic complications, cardiovascular disease by far was found to have the greatest proportion of direct costs and more than half the mortality-related costs of the condition [10]. In a recent paper [11] it was shown that the per-person annual costs associated with Type II diabetes increased by more than $50 \%$ when cardiovascular complications started to appear, and by $360 \%$ when a major cardiovascular event occurred. Abnormal renal function increased diabetes treatment costs by $65 \%$, and end-stage renal disease by $771 \%$. Due to the large number of complications associated with diabetes, diabetic patients account for 1 in every $\$ 7$ spent on healthcare in the United States [12].

Up-to-date and comprehensive economic data on the costs of diabetes are required for policy decisions, in order to optimise the allocation of resources and to evaluate the success of different approaches for disease management. While the economic aspects of Type II diabetes have been widely studied in the United States, information from Europe has been fairly limited until recently. There have been a few studies from European countries, for example two from Sweden $[13,14]$ and two from the United Kingdom $[15,16]$. Although the information is difficult to compare and contrast, due to inconsistencies in re- search objectives, methods and the data sources used, all studies highlight the substantial healthcare costs associated with diabetes. For example, these and many other studies do not make a distinction between Type I (insulin-dependent) and Type II (non-insulindependent) diabetes mellitus. While these separate conditions have similar long-term consequences, they affect different, albeit overlapping age groups and require different treatment strategies. The approach taken to measure the cost of diabetes is also variable. Some studies estimate the cost of diabetes, while others measure the total healthcare costs for diabetic patients, including both diabetes-related and non-diabetes-related events. Furthermore, some studies use the main diagnosis to attribute costs to diabetes, while other studies use aetiological fractions.

The CODE- 2 study is the first coordinated attempt to measure the cost of people with Type II diabetes in Europe. This study measured total healthcare costs for more than 7000 people with Type II diabetes in eight European countries - Belgium, France, Germany, Italy, the Netherlands, Spain, Sweden and the United Kingdom using a bottom-up, prevalence-based design. A number of secondary objectives were also addressed, including: the distribution of total cost and the main components of cost (ambulatory care, drugs and hospitalisation); a review of current management practice; an assessment of the impact of complications on cost; and from the patient perspective, consideration of quality of life, satisfaction with treatment and self testing.

The collection of data directly from patients to assess the health-related quality of life (HRQoL) associated with the disease added another unique and important aspect to the study [17]. Whereas the primary objective focused on measuring the consequences of the condition with respect to direct healthcare expenditure, the secondary objectives considered areas of possible intervention, providing opportunities to maximise future use of resources.

\section{Subjects and methods}

Study design. The design of the study (Fig. 1) was developed in consultation with an extensive panel of more than 100 experts including diabetologists, endocrinologists, health economists, general or primary-care practitioners and epidemiologists. In the design and implementation process, effort was made to ensure consistency across the eight countries in terms of data specification, data collection tools and methods, sampling design, and the analysis and reporting of results. Data was collected between January 1999 and June 1999 and covered a minimum period of 6 months, retrospectively. Estimates of healthcare utilisation and costs were projected for a 12 -month period. Design modifications in accordance with differences in national healthcare systems were made when necessary, although limited as much as possible. The study design optimised the collection of data at the national level while maintaining maximum international comparability. 


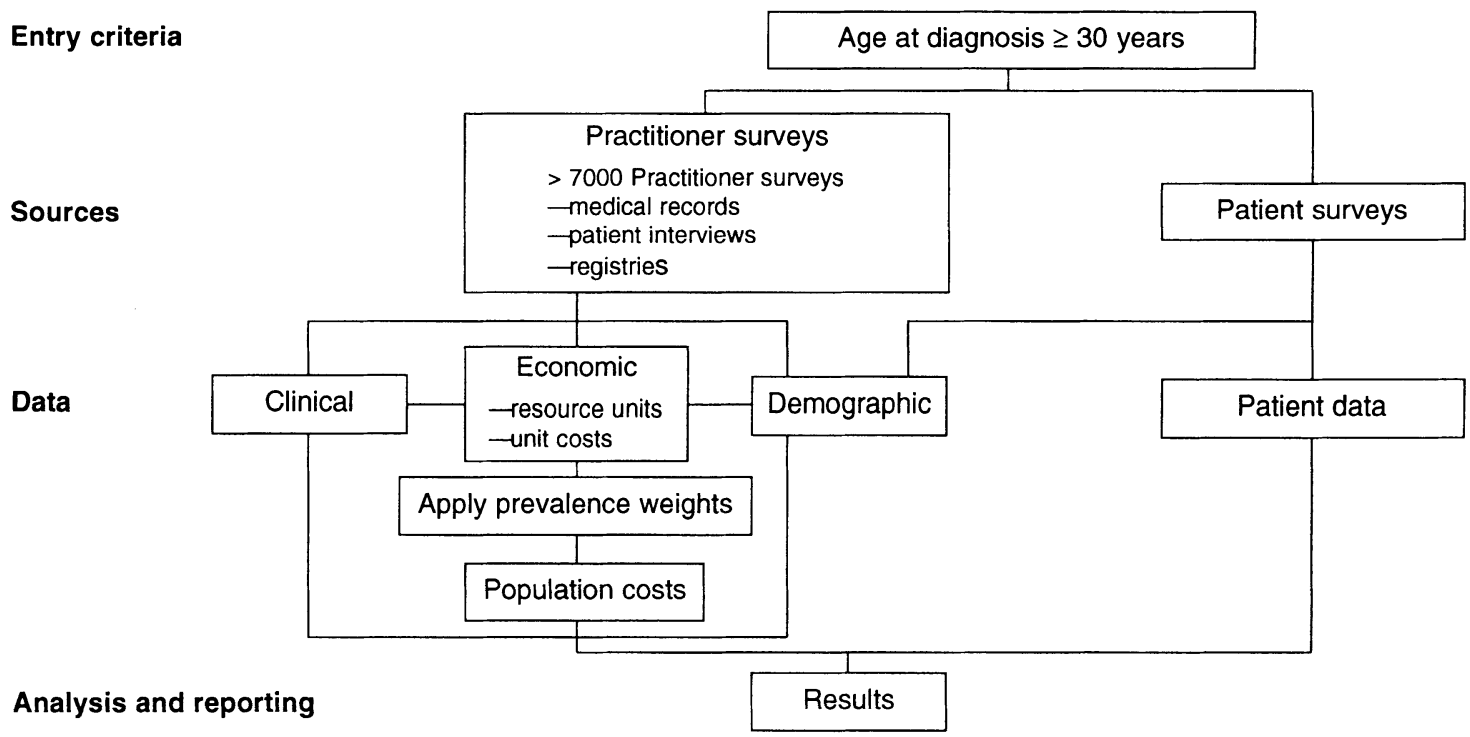

Fig. 1. Overview of the CODE-2 study protocol

After consultation with independent national experts and a review of existing epidemiological data, four of the eight countries (Belgium, France, Germany, and Italy) decided to collect data using stratified sampling techniques. Prior to the collection of CODE-2 data, Belgium, Germany, and Italy did a national survey of physicians, to ascertain the prevalence of known complications of Type II diabetes. In contrast, France used a national survey (ECODIA) [18], which included a representative sample of more than 4000 patients with Type II diabetes, to derive the sampling weights for the stratification. All definitions of microvascular and macrovascular complications were consistent across the four countries. These definitions are reported elsewhere in this supplement [19]. The remaining four countries collected data using a random sampling approach on the basis of known complications of Type II diabetes.

Study protocol. The data was collected by means of two questionnaires specially designed for practitioners and patients: the general practitioner (GP) questionnaire was used to collect information on direct medical resource utilisation and clinical data based on practitioner-held records; and the patient questionnaire provided complimentary socio-economic information.

Data collected from practitioners included clinical, economic and demographic information, while data collected from patients included indirect and direct non-medical resource use, quality of life (QoL), satisfaction with current diabetes treatment, and information on self-testing of blood and urine sugar concentrations.

The overall direct healthcare costs were calculated by multiplying the quantities of the resource used with the unit price of each resource. To determine the direct cost of the Type II diabetic patients who were sampled, estimates of the number of physician visits, paramedical visits, tests and procedures, hospitalisations, days in hospital, emergency room visits and drug use were multiplied by a unit cost for each country (Table 1). In general, the costs for standard resources are relatively similar between the countries in the study and any variation is usually the result of differences in accounting procedures. For example, the baseline costs for GP visits in Sweden appear rela- tively high; however, the value includes all the costs associated with an average visit, including all tests and procedures. The costs for these tests and procedures are calculated separately in other countries. To extrapolate the sample costs to population size in order to calculate the total direct healthcare cost for each country, the per-patient costs were multiplied by national prevalence weights:

- $\mathrm{P}_{\mathrm{i}} \times \mathrm{Q}_{\mathrm{i}}=$ Cost $_{\mathrm{i}}$

- Cost $_{i} \times$ prevalence weights $=$ population cost

- $\mathrm{P}=$ price, $\mathrm{Q}=$ resource use, and $\mathrm{i}=1-n$ (where $n=$ number of cost items)

All local currency total costs were converted to Euros using the official Euro conversion rate as of January 1, 1999. However, due to variations in the healthcare system in Germany, this extrapolation method using the values in Table 1 was not applicable for visits to GPs, diabetologists, or other specialists. These values included only the cost of the visit itself and the fees for each procedure are at an additional cost.

\section{Results}

Patients. The demographic data from CODE-2 are detailed in Table 2 and the Type II diabetes prevalence data, which was used for extrapolation of sample costs, are presented in Table 3. The demographics of the study population were relatively similar between each of the countries with a few notable exceptions. The study population of the United Kingdom had a higher proportion of male than female patients in comparison with the other countries. In addition, the time since diagnosis was higher than the 9-year average in Italy (13 years) and lower among the Dutch study population (6 years). The average age and body mass index (BMI) data were similar across all eight countries. The majority of patients recruited in the study were older than 65 years of age and were receiving treatment with oral antidiabetic agents (59\%) (Fig. 2). The greatest proportion of oral pharmacotherapy was observed in France $(84.69 \%)$ and the smallest in Sweden $(42.45 \%)$. 
Table 1. National costs for CODE-2 resource units

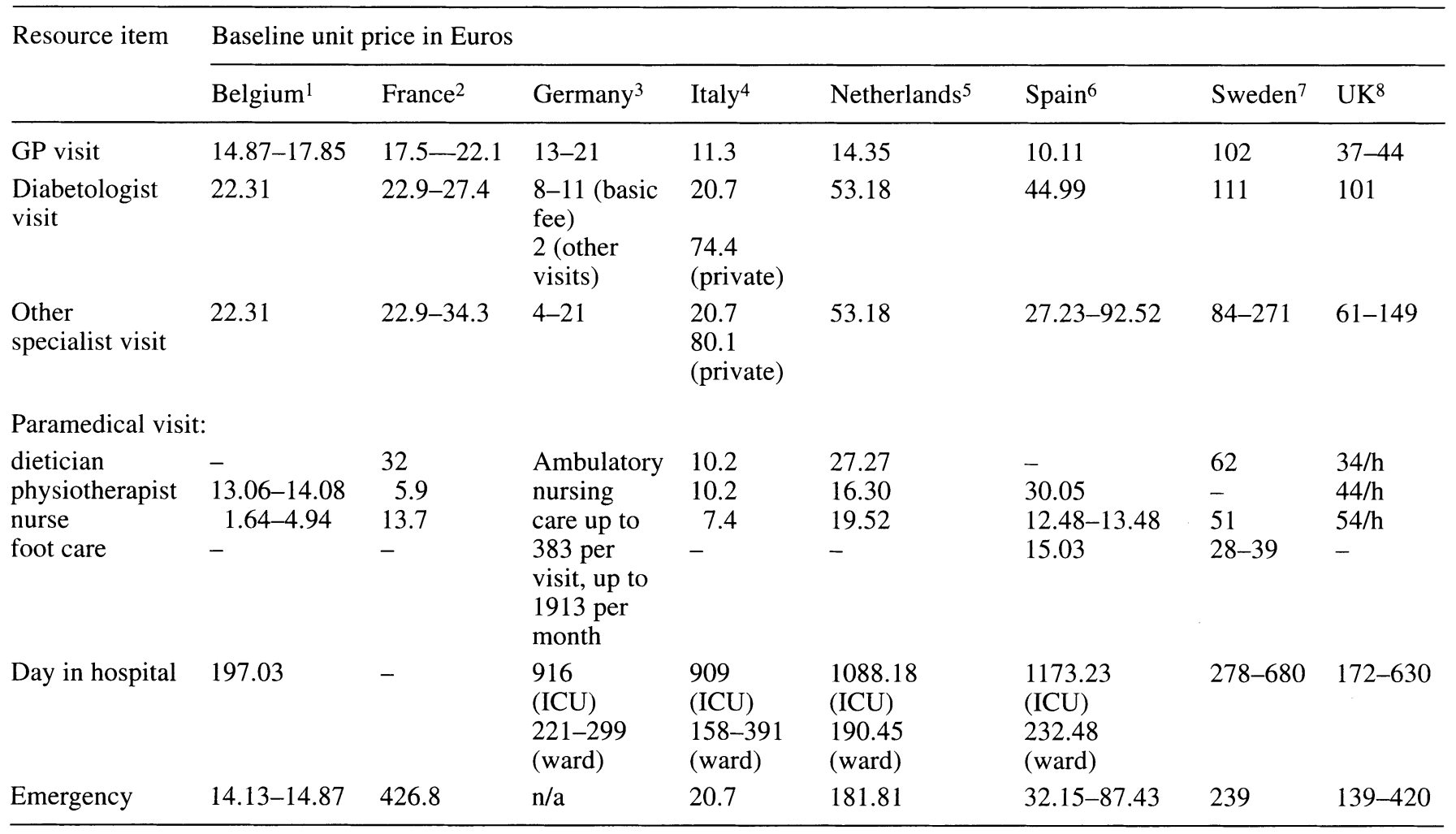

Range presented where more than one price is possible, GP, general practitioner (primary care physician); ICU, Intensive Care Unit; n/a, not applicable; -, no data available

Data sources:

${ }^{1}$ Cost data for medical and paramedical visits - Tarifering van de Geneeskundige Verstrekkingen (RIZIV/INAMI, 1998), Hospital costs were based on a weighted average cost per hospital-bed day from Ministry of Health and hospital cost database

2 Cost for all medical procedures and ambulatory care provided by Nomenclature Générale des Actes Professionnels (NGAP) with 1999 values, and full values from the Ministry of Health through the National Hospital Costs Survey (1997 with latest data published in 1999). Micro-costing used where published costs and tariffs were unavailable

3 All prices and charges based on reimbursement fees taken from the Einheitlicher Bewertungsmaßstab (1998 values), the German Association of Hospitals (1996 values), Nursing Care Insurance and the Rote Liste for medications. For visits to GPs, diabetologists, or other specialists, the values included only the cost of the visit itself and the fees for each procedure carried out must be added

4 General practitioner visits are calculated based on Servizio Sanitario Nationale values from 1998; information on total vis-

Total healthcare expenditure. Total costs of Type II diabetes for the eight countries was estimated to be EUR 29 billion (1999 values). The annual costs per patient with Type II diabetes was estimated to be EUR 2834 (Table 4). The Netherlands was found to have the lowest expenditure per patient (EUR 1827), while Italy had the highest annual cost (EUR 2991). In contrast, the prevalence of Type II diabetes in the gen- its was obtained from the Servizio Presrizioni Mediche (1996 values equivalent to 1998); hospitalisation costs were based on data obtained from the Servizio Sistema Informativo - Lombardy region. Where data were not directly available, information was obtained by personnel communication from an expert panel or survey

5 Unit cost for GP visits based on tariffs from private and public health insurance from Centraal Orgaan Tarieven Gezondheidszorg (COTG), 1998; Unit costs for specialists were based on weighted average costs for consultations at hospitals; similar methodology was used to assign unit costs to hospitalday costs

6 Cost data were obtained predominantly form the SOIKOS database of Health Unit Costs. Costs were inflated to 1998 values were only available for previous years. Where data was not available personnel communication was included from relevant sources (1999 values)

7 Swedish sources included published folders of the Federation of County Councils (1993 and 1996 values inflated to 1998 values), Hospital Price Lists (1998 values), and personnel communications from relevant practitioners

8 Principal sources include the Unit Cost of Health and Social Care 1998 and the Office of Health Economics Compendium of Health Statistics (1994/95 values inflated to 1997/98 prices)

eral population was estimated to range from $1.7 \%$ in the Netherlands to $4.2 \%$ in Germany (Table 3). On average, $3 \%$ of the population with Type II diabetes in the countries surveyed accounted for $5 \%$ of the total healthcare expenditure [25], where available data from the Organisation for Economic Co-Operation and Development (OECD) was used to estimate the percentage of total healthcare budget spent on Type II 
Table 2. CODE-2 demographic data

\begin{tabular}{|c|c|c|c|c|c|}
\hline Country & $\begin{array}{l}\text { Study population } \\
\text { (patients) }\end{array}$ & $\begin{array}{l}\text { Age (years) } \\
\pm \mathrm{SD}\end{array}$ & $\begin{array}{l}\% \text { Sex } \\
(\mathrm{M} / \mathrm{F})\end{array}$ & $\begin{array}{l}\text { Mean BMI } \\
\left(\mathrm{kg} / \mathrm{m}^{2}\right) \pm \mathrm{SD}\end{array}$ & $\begin{array}{l}\text { Mean time since } \\
\text { diagnosis (years) } \pm S D\end{array}$ \\
\hline Belgium & 735 & $66.0 \pm 11.7$ & $42 / 58$ & $29.3 \pm 6.1$ & $7.6 \pm 6.9$ \\
\hline Germany & 809 & $67.1 \pm 1.6$ & $48 / 52$ & $28.4 \pm 0.1$ & $8.0 \pm 0.9$ \\
\hline Italy & 1263 & $65.7 \pm 9.5$ & $50 / 50$ & $28.0 \pm 4.6$ & $13.0 \pm 8.7$ \\
\hline Netherlands & 909 & $64.8 \pm 11.6$ & $49 / 51$ & $28.1 \pm 5.1$ & $6.4 \pm 6.0$ \\
\hline UK & 756 & $63.3 \pm 12.0$ & $61 / 39$ & $30.0 \pm 5.8$ & $7.8 \pm 7.0$ \\
\hline CODE- 2 average & 7000 & 65.9 & 50 & 28.7 & 9.3 \\
\hline
\end{tabular}

Table 3. Prevalence of Type II diabetes in CODE-2 study countries

\begin{tabular}{llll}
\hline Country & \multicolumn{2}{l}{ Prevalence of Type II (non-insulin-dependent) diabetes mellitus } \\
\cline { 2 - 3 } & Number of patients & $\%$ of population \\
\hline Belgium & 332000 & 3.3 & 2.2 \\
France & 1.3 million & 4.2 & {$[18]$} \\
Germany & 3.5 million & 3.0 & {$[20]$} \\
Italy & 1.7 million & 1.7 & {$[21]$} \\
Netherlands & 235000 & 3.9 & {$[22]$} \\
Spain & 1.5 million & 3.6 & {$[23]$} \\
Sweden & 325000 & 2.0 & \\
UK & 1.2 million & 3.0 (average) & \\
All CODE-2 countries & $>10$ million &
\end{tabular}

Diet and exercise Oral antidiabetic drug Insulin alone or in combination

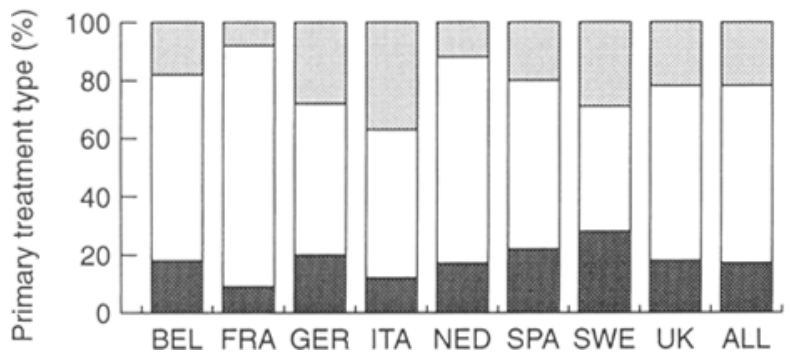

Fig. 2. Primary Type II diabetes treatment types by country

diabetes (Table 4). Comparing this study with the American study [12], some differences can be noticed. Whereas the average prevalence in the European countries was 3\%, the prevalence in the United States was $4.5 \%$. Furthermore, diabetic patients accounted for a larger share of the total health care expenditures in the United States compared to Europe (15\% vs $5 \%$ ). However, it is important to note the danger in comparing studies carried out in different countries in different years using different methodology. For example, the American study used a database as the main data source, it was carried out in 1992, it included both Type I and Type II diabetes and more resources than the CODE-2 study (e.g. dental care and medical equipment). In addition, relatively expensive inpatient care accounted for a larger fraction in the United States compared to the European average (63\% vs $55 \%)$.

Distribution of costs. To investigate the distribution of costs, resource use was separated into three categories:

(1) ambulatory costs were defined as the sum of all costs of visits to GPs, diabetologists and other specialists (e.g. cardiologists), paramedical practitioners (e.g. physiotherapists, nurses, dieticians), accident and emergency departments, and all tests and procedures (e.g. blood tests, blood pressure measurements, etc);

(2) hospitalisation costs were defined as the sum of costs of all admissions to hospital (for example, based on length of stay, DRG: diagnosis-related group or ICD-9: International Classification of Diseases);

(3) drug costs, defined as the sum of costs of all drugs prescribed by GPs and specialists in outpatient settings. 
Table 4. Yearly direct medical costs for people with Type II diabetes

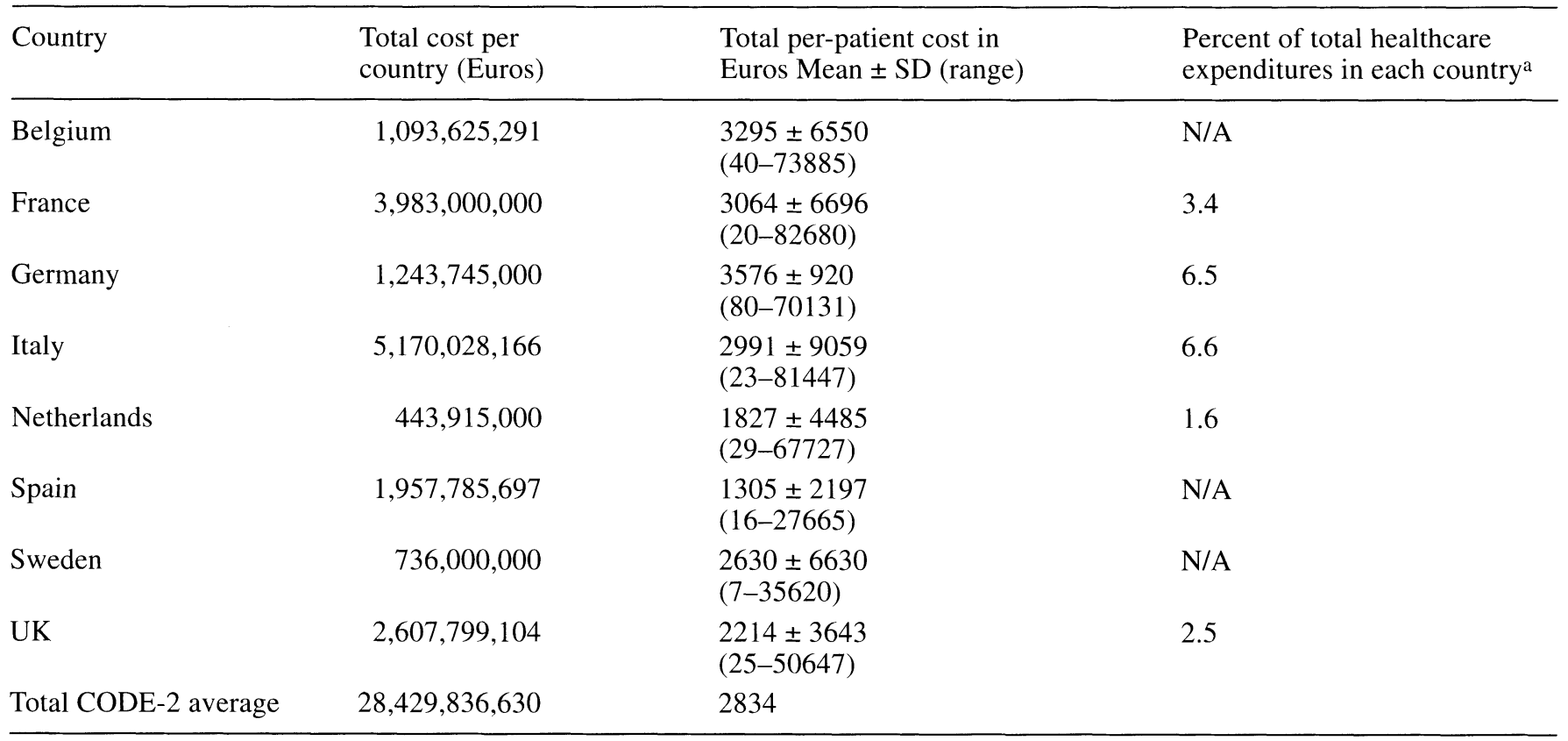

a Using 1997 OECD total current expenditure on health

Table 5. Distribution of annual per-patient costs by main resource category in Euros ${ }^{\mathrm{a}}$

\begin{tabular}{|c|c|c|c|c|}
\hline \multirow[t]{2}{*}{ Country } & \multicolumn{4}{|c|}{ Resource category } \\
\hline & $\begin{array}{l}\text { Hospitalisation } \\
(\text { mean } \pm \mathrm{SD})\end{array}$ & $\begin{array}{l}\text { Ambulatory care } \\
(\text { mean } \pm \mathrm{SD})\end{array}$ & $\begin{array}{l}\text { Oral antidiabetic drugs } \\
\text { only }(\text { mean } \pm \text { SD) }\end{array}$ & $\begin{array}{l}\text { All other drugs } \\
(\text { mean })^{\mathrm{a}}\end{array}$ \\
\hline Belgium & $1791 \pm 5864$ & $603 \pm 931$ & $127 \pm 114$ & 774 \\
\hline France & $1540 \pm 6252$ & $683 \pm 1433$ & $207 \pm 169$ & 633 \\
\hline Germany & $2173 \pm 755$ & $388 \pm 47$ & $119 \pm 8$ & 896 \\
\hline Spain & $417 \pm 1960$ & $334 \pm 307$ & $61 \pm 101$ & 494 \\
\hline Sweden & $1116 \pm 6135$ & $813 \pm 1088$ & $41 \pm 37$ & 661 \\
\hline UK & $769 \pm 4015$ & $835 \pm 775$ & $60 \pm 71$ & 519 \\
\hline CODE-2 Average & 1333 & 603 & 103 & 476 \\
\hline
\end{tabular}

a No SD values available due to method of calculation; SD values for individual drug categories see Table 8 projected from 6-month survey data

Table 6. Mean cost per-patient by type of treatment in Euros

\begin{tabular}{llll}
\hline \multirow{2}{*}{ Country } & \multicolumn{2}{l}{ Primary treatment type } & \\
\cline { 2 - 4 } & Diet and exercise alone & Oral antidiabetic drugs & Insulin alone or in combination \\
\hline Belgium & 3120 & 2594 & 5724 \\
France & 1142 & 3039 & 5913 \\
Germany & 3004 & 2867 & 4997 \\
Italy & 4329 & 2445 & 3374 \\
Netherlands & 1142 & 1737 & 2973 \\
Spain & 886 & 1103 & 2309 \\
Sweden & 1612 & 2044 & 4215 \\
UK & 1501 & 2064 & 2676 \\
CODE-2 average & 2419 & 2400 & 4116 \\
\hline
\end{tabular}


Table 7. Percentage or patients hospitalised, and overall number of days if hospitalised

\begin{tabular}{llr}
\hline Country & $\begin{array}{l}\text { Percentage hospitalised in study period } \\
(6 \text { months })\end{array}$ & $\begin{array}{l}\text { Mean length of stay per hospitalisation } \\
\text { in days }\end{array}$ \\
\hline Belgium & $18.5 \%$ & 20 \\
France & $13.1 \%$ & 9 \\
Germany & $12.7 \%$ & 18 \\
Italy & $17.8 \%$ & 13 \\
Netherlands & $7.7 \%$ & 12 \\
Spain & $8.3 \%$ & 8 \\
Sweden & $12.5 \%$ & 7 \\
UK & $11.4 \%$ & 7 \\
CODE-2 average & $12.9 \%$ & 13 \\
\hline
\end{tabular}

Table 8. Mean drug costs per patient by country in Euros

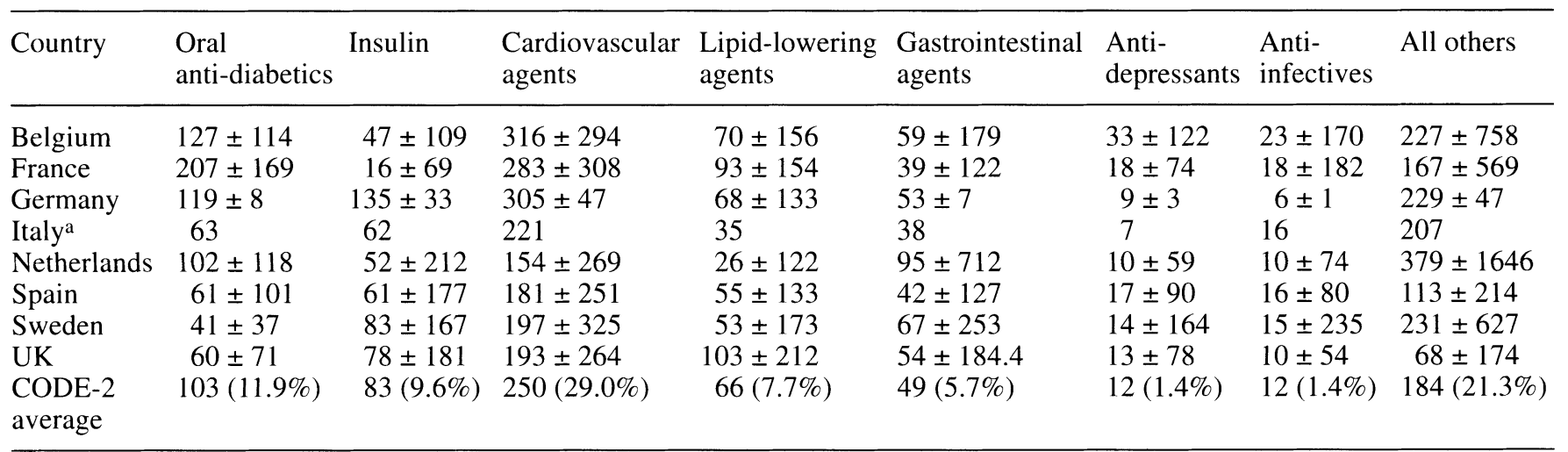

a SD values not available from Italian data

Drug costs applied to entire diabetic population (means \pm SD)

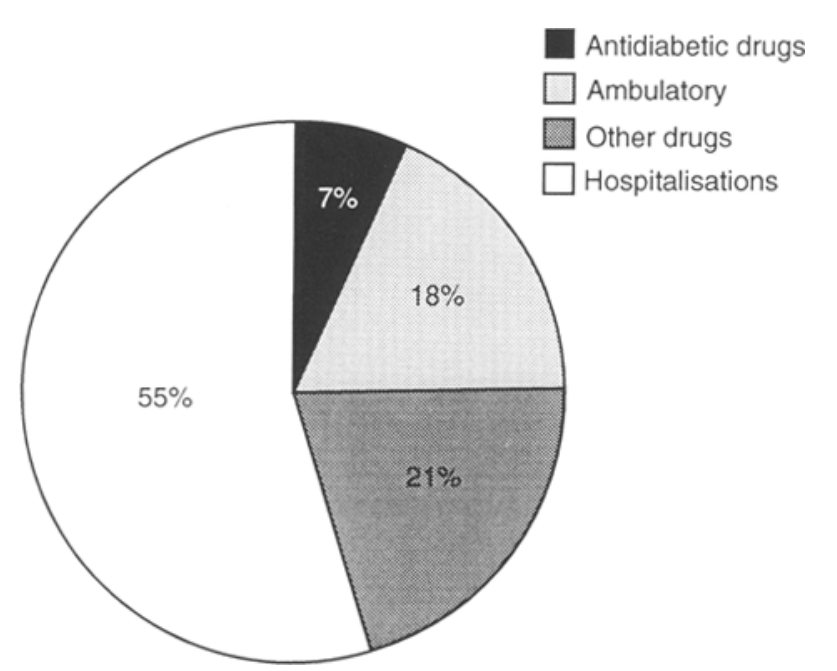

Fig. 3. Distribution of overall costs for individuals with Type II diabetes

The distribution of the overall direct healthcare costs for all countries in the CODE-2 study is shown in Figure 3 the direct costs per patient represented by country and for the total CODE-2 population are illustrated in Table 5 and mean per patient cost by treat-

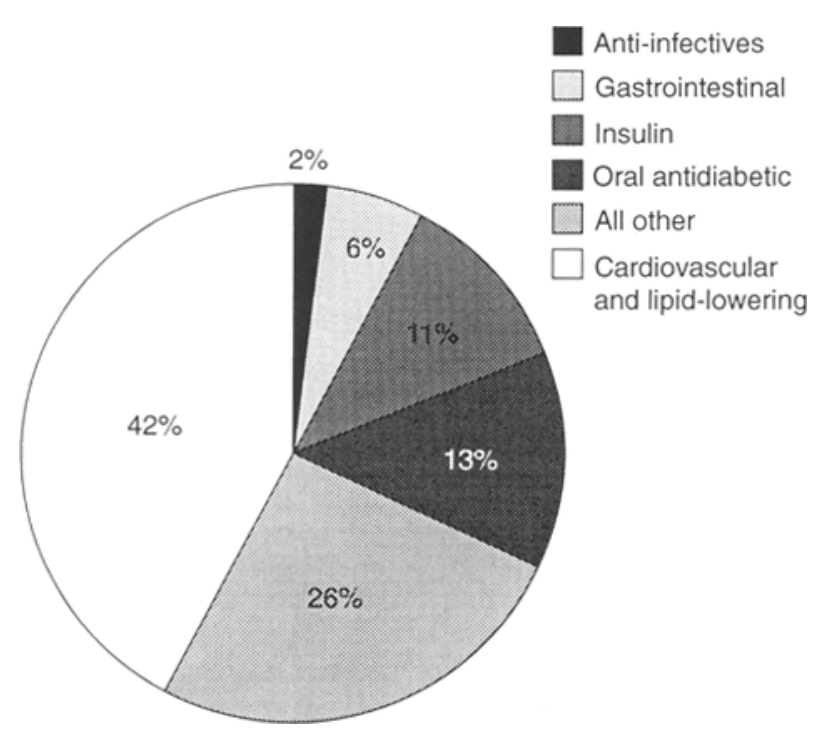

Fig. 4. Distribution of overall drug costs for individuals with Type II diabetes

ment type is detailed in Table 6. Hospitalisations accounted for the greatest proportion of costs $(55 \%$, range $30-65 \%$ ). In total, $13 \%$ of the study population were hospitalised in the 6-month study period. (Table 7). Of the categories investigated, ambulatory 
costs represented the smallest proportion of overall direct healthcare costs (18\%) (Fig. 3). The overall cost of drug therapy in these patients of EUR 7.9 billion represented $27 \%$ of the total healthcare costs. Although over $60 \%$ of patients were receiving oral antidiabetic agents, representing the largest primary treatment receiving drug therapy, the cost of these drugs accounted for only $4 \%$ of the total healthcare costs. When the components of the total drug cost category were considered in isolation, cardiovascular and lipid-lowering agents represented the largest proportion (42\%) with oral antidiabetic drugs accounting for only $13 \%$ and insulin $11 \%$ of total drug costs (Fig. 4, Table 8).

\section{Discussion}

For the first time, the CODE-2 study has shown a comprehensive and practical insight into the costs of people with Type II diabetes across different European countries. The design of the study allowed for the direct comparison of international data on healthcare costs. The 6-month retrospective design could have some disadvantages. Recall bias could have been a problem but since the questionnaires relied mostly on stored information, such as medical records, this problem is minor. Collecting information during a six month period and extrapolating to one year disregards any seasonal variation which might exist. The CODE-2 study showed that more than 10 million people with Type II diabetes across eight European countries cost over EUR 29 billion in 1999. Of the direct costs, hospitalisation alone accounted for the largest proportion, while drug costs for managing the disease were relatively low. Indeed, the oral drug therapy for the management of glycaemic control accounted for about $4 \%$ of overall costs in Type II diabetic patients. The single factor having the largest impact on costs of patients with Type II diabetic is the presence of different diabetes-related late complications. The findings from the CODE-2 study therefore confirm that in all eight of the European countries studied, Type II diabetes is a costly and burdensome disease.

\section{References}

1. McCarty D, Zimmet P (1994) Diabetes 1994 to 2010: global estimates and projections. International Diabetes Institute, Melbourne

2. Amos AF, McCarty D, Zimmet P (1997) The rising global burden of diabetes and its complications: estimates and projections to the year 2010. Diabet Med 14 [Suppl 5]: S7-S85

3. King H, Aubert RE, Herman WH (1998) Global burden of diabetes, 1995-2025: prevelance, numerical estimates, and projections. Diabetes Care 21:1414-1431

4. Ray N, Willis S, Thamer M (1993) Direct and indirect costs of diabetes in the United States in 1992. American Diabetes Association, Alexandria
5. Harris MI, Flegal KM, Cowie CC et al. (1998) Prevalence of diabetes, impaired fasting glucose, and impaired glucose tolerance in U.S. adults. The Third National Health and Nutrition Examination Survey, 1988-1994. Diabetes Care 21:518-524

6. United Kingdom Prospective Diabetes Study (UKPDS) Group (1998) Intensive blood-glucose control with sulphonylureas or insulin compared with conventional treatment and risk of complications in patients with type 2 diabetes (UKPDS 33). Lancet 352:837-853

7. Simanis JG (1987) Health care expenditures: international comparisons, 1970-80. Soc Secur Bull 50:19-24

8. Organization for Economic Cooperation and Development (1990) Health care systems in transition; the search for efficiency. Organization for Economic Cooperation and Development (OECD) Social Policy Studies No. 7. Paris pp 129-135

9. Laing W, Williams R (1989) Diabetes: a model for health care management. Office of Health Economics, London

10. American Diabetes Association (1998) Economic consequences of diabetes in the U.S. in 1997. Diabetes Care 21:296-309

11. Brown JB, Pedula KL, Bakst AW (1999) The progressive cost of complications in type 2 diabetes mellitus. Arch Intern Med 159:1873-1880

12. Rubin RJ, Altman WM, Mendelson DN (1994) Health care expenditures for people with diabetes mellitus. J Endocrinal Metab 78:809A-809A

13. Jönsson B (1983) Diabetes - the cost of illness and the cost of control. Acta Med Scand 671 [Suppl]:19-27

14. Henriksson F, Jönsson B (1998) Diabetes: the cost of illness in Sweden. J Internal Med 244:461-468

15. Marks L (1996) Counting the Cost - The real impact of non-insulin dependent diabetes. Kings Fund Report commissioned by the British Diabetic Association, London

16. Laing W, Williams R (1989) Diabetes: a model for health care management. No 92 in a series of papers on current health problems. Office of Health Economics, London

17. Koopmanschap M (2002) Coping with Type 2 diabetes: the patient perspective. Diabetologia supplement (this issue)

18. Detournay B, Vauzelle-Kervroedan F, Charles MA et al. (1999) Epidemiology, management and costs of Type 2 diabetes in France, in 1998. Diabetes Metab 25:356-365

19. Williams R, Van Gaa L, Lucioni C (2002) Assessing the impact of complications on the costs of Type 2 diabetes. Diabetologia supplement (this issue)

20. Gesundheitsbericht für Deutschland (1998) Statistisches Bundesamt, Gesundheitsberichterstattung des Bundes, Metzler-Poeshel, Stuttgart

21. Vaccaro O, Bonora E, Bruno G, Garancini MP, Muntoni S (1996) L'epidemiologia del diabete non-insulino-dipendente e della ridotta tolleranza al glucosio II diabete in Italia. Kurtis Milano, pp 17-30

22. Baan CA, Bonneux L, Ruwaard D, Feskens EJM (1998) The prevalence of diabetes mellitus in the Netherlands. A quantitative review. Eur J Public Health 8:210-216

23. The Regional Autonomous Government of Catalunya (1997) Prevalenca de diabetis mellitus no insulinodependent a Catalunya. Bulleti Epidemiologic de Catalunya. Consell Asesor sobre la Diabetis e Catalunya Vol 18, No. 3, Department de Sanitat i Seguretat Social Catalunya

24. Berger B, Stenstrom G, Sundkvist G (1999) Incidence, prevalence, and mortality of diabetes in a large population. Diabetes Care 22:773-777

25. Organization for Economic Cooperation and Development (2000) OECD Health data 00 CD ROM. Organization for Economic Cooperation and Development, Paris 